\title{
Equine Sarcoid: Epidemiology and its Clinical Impact in Working Donkeys in Selected Districts of Central Ethiopia
}

\author{
Debebe Gebre $^{1}$, Ayele Gizachewu ${ }^{1}$ and Jalel Negero ${ }^{2^{*}}$ \\ ${ }^{1}$ Faculty of Veterinary Medicine, College of Veterinary Medicine and Agriculture, Addis Ababa University, PO Box 34, Bishoftu, Ethiopia \\ ${ }^{2}$ School of Veterinary Medicine, College of Agriculture and Veterinary Medicine, Jimma University, PO Box: 307, Jimma, Ethiopia
}

"Corresponding author: Jalel Negero, School of Veterinary Medicine, College of Agriculture and Veterinary Medicine, Jimma University, PO Box: 307, Jimma, Ethiopia, Tel: 020-25869599; E-mail: negerojalel@gmail.com

Rec date: April 27, 2018; Acc date: April 30, 2018; Pub date: May 01, 2018

Copyright: (c) 2018 Gebre D, et al. This is an open-access article distributed under the terms of the Creative Commons Attribution License, which permits unrestricted use, distribution, and reproduction in any medium, provided the original author and source are credited.

\begin{abstract}
Objective: To assess Equine Sarcoid: Epidemiology and its clinical impact in working donkeys in selected districts of central Ethiopia.

Methods: A Cross sectional study was conducted between November, 2009 to April 2010 to assess the epidemiology and clinical impact of equine sarcoids in working donkeys. A structured questionnaire survey was also designed to collect data on current status of sarcoid on donkeys. A random sampling technique was used to select a total of 394 working donkeys in this study. Selected donkeys were clinically examined properly for visible skin lesion.

Results: Among a total of donkeys observed during study period, 31 (7.9\%) were diagnosed sarcoid positive. A Chi square analysis was used to determine degree of association between risk factors and prevalence of sarcoid infection. The analysis revealed that sarcoid in working donkeys were significantly higher $(P<0.05)$ than that of nonworking donkeys. About $83.9 \%$ of sarcoid were increasing in size, while $16.1 \%$ sarcoid were static in nature. The invasive nature of sarcoid and its complication resulted in apparent blindness, difficulties in locomotion, urination, grazing, mastication and deification.
\end{abstract}

Conclusion: The result of present work suggest that the prevalence impact of equine sarcoid on health and welfare of working donkeys was considerable and deserves attention.

Keywords: Central Ethiopia; Equine; Health and welfare; Prevalence; Sarcoid; Working donkeys

\section{Introduction}

Sarcoid is one of dermatological problems, most commonly detected skin tumor in donkeys. It can be defined as a unique local invasive, benign neoplastic like tumor of the skin with available epidermal component which has a high propensity for recurrence $[1,2]$ and can occur as single or multiple lesions in difference forms ranging from small wart-like lesions to large ulcerated fibers growths. The economic repercussion can be great: besides the cosmetic aspect, the normal use of donkeys can be hindered, especially when tumor is located at the level of girth and bridle, distal limbs, corner of the mouth, eyelids [3]. It is recognized as having six different clinical forms which are occult, veracious, nodular, fibroblastic, mixed and malevolent sarcoid [4]. Fibroblastic sarcoids are characteristic of aggressive, fleshy, ulcerated appearance and local infiltration is common. In spite of their aggressive appearance they do not metastasized but can spread locally in the dermis by local invasion or extension [5].

The etiology of equine sarcoid is equivocal; however, the bovine papilloma virus (BPV) is hypothesed as the etiological agent of equine sarcoid. Precise mode of transmission of BPV in equine sarcoids remains unclear but suggested that it is transmitted by direct or indirect contact with other infected horses and cattle. Insects may also play a role [6,7]. Risk factors remain unclear, although major histocompatibility complex (MHC) type, age and sex are emerging as worthy of greater scrutiny [7]. There are controversial reports on their age group of equines affected by sarcoids that would appear that young males appear to be at more risk of disease. Marconne and Knottenbelt [5] reported that $70 \%$ of sarcoids were focused only on donkeys presented to DHWP (Donkeys Health and Welfare Project) clinic at the Addis Ababa University, Faculty of Veterinary Medicine. Therefore, this would make the available information less powerful to give the correct clinical picture of the disease. Thus, current study carried out with the objective to assess Equine Sarcoid: Epidemiology and its clinical impact in working donkeys in selected districts of central Ethiopia.

\section{Materials and Methods}

\section{Study area}

The study was conducted in two different Districts, namely Ada'a and Akaki of central Ethiopia. This selection was made based on their higher donkey population and role of donkeys in the livelihood of farmers. A total of 11 kebeles (Kebele: the lowest administrative unit in Ethiopia) were randomly selected from the total of 54 kebeles in both district were considered on the basis of total donkey population presented in the Kebeles depending on feasibility and affordability or cost. Five of kebeles were from Akaki namely Abu Sera, Gelan Arebsa, 
Page 2 of 4

Gogecha, Insilale finche and Wodeso Werebo; and six of kebeles were from Ada'a namely Chalab Silase, Dukem koticha, Garbicha, Genda gorba, Giche gerebabe and Tadecha.

\section{Study design and population}

A cross-sectional type of study was conducted to establish clinical prevalence of sarcoid and to assess its associated risk factors in the study area in a different age, sex and working donkeys living in different condition in this study area. A structured questioner survey was also designed to collect data on current status of sarcoid on donkeys that are found in central land of Ethiopia. The questionnaire was directly forwarded by interviewing owners presenting their donkeys to the site for mass deworming by the Donkeys Health and Welfare Project program.

\section{Sampling methodology}

A random sampling technique was used to select study population. Study population selected randomly based on total population presented in each kebele for mass deworming program. The randomly selected donkeys were thoroughly diagnosed through inspection and palpation of the whole body for the presence or absence sarcoid and other cases resembling sarcoids. Here donkeys with clinical appearance of sarcoids were identified and classified by its morphological characteristics. The age, sex, working condition and area of donkeys were recorded.

\section{Sample size determination}

For this particular study the sample size was determined for a define precision and level of confidence and calculated according the formula by Thrushfield [8]. Since there was no previous estimated prevalence of sarcoid in the areas of current study were carried out; $50 \%$ prevalence was expected with desired absolute precision $5 \%$ and $95 \%$ confidence interval were used to determine the minimum sample size. For this study a total of 384 donkeys were included from the two study areas.

$$
\mathrm{N}=1.96^{2} \mathrm{P}_{\exp }\left(1-\mathrm{P}_{\exp }\right) / \mathrm{d}^{2}
$$

Where, $n=384 ; n=$ sample size of the study population; $d=$ Absolute desired precision; $\mathrm{p}=$ previous/expected prevalence in the study area; $\mathrm{CI}=$ confidence interval; $1.96^{2}=\mathrm{Z}$-value for the confidence levels.

\section{Data management and analysis}

Microsoft excel spread sheet program was used to store all the data, filtered, coded and recorded before transferred and analyzed by using Chi-square test. Descriptive statistics was used to summarize the data in the tables. The prevalence was calculated by dividing the number of donkeys that were clinically tested positive by the total number of donkey observed. Pearson Chi-square test was used to test the significance of relationship between risk factors and sarcoid positive generally with a significance level of $P<0.05$ at $95 \%$ confidence level.

\section{Results}

\section{Prevalence}

Out of the total of 394 donkeys examined during the study period $31(7.9 \%)$ were diagnosed with sarcoid positive.

\section{Risk factors}

District: Although the prevalence of sarcoid was higher in Ada'a as compare to Akaki, this was no significant difference $(\mathrm{P}=0.428)$ (Table $1)$.

\begin{tabular}{|c|c|c|c|c|c|}
\hline $\begin{array}{l}\text { Distric } \\
t\end{array}$ & Study kebeles & $\begin{array}{l}\text { No. of } \\
\text { donkeys } \\
\text { examine } \\
\text { d }\end{array}$ & $\begin{array}{l}\text { No. of } \\
\text { sarcoid } \\
\text { positive }\end{array}$ & Prevalence \% & P-value \\
\hline \multirow[t]{6}{*}{ Ada'a } & Chaleba Silase & 36 & 4 & 11.1 & \multirow[t]{11}{*}{0.428} \\
\hline & $\begin{array}{l}\text { Dukame } \\
\text { Koticha }\end{array}$ & 42 & 3 & 7.1 & \\
\hline & Garbicha & 38 & 3 & 7.9 & \\
\hline & Ganda gorba & 47 & 3 & 6.4 & \\
\hline & Giche garbaba & 33 & 4 & 12.1 & \\
\hline & Tedecha & 41 & 4 & 9.7 & \\
\hline \multirow[t]{5}{*}{ Akaki } & Abosera & 31 & 4 & 12.9 & \\
\hline & Gelan & 32 & 2 & 6.3 & \\
\hline & Gogecha & 30 & 1 & 3.3 & \\
\hline & Insillale & 29 & 2 & 6.9 & \\
\hline & Wodesowarab & 25 & 1 & 4 & \\
\hline \multicolumn{2}{|l|}{ Total } & 394 & 31 & 7.8 & \\
\hline
\end{tabular}

Table 1: Prevalence of equine sarcoid in different districts of central Ethiopia.

Sex, age and service category: Even though there was no statistically $(p>0.05)$ significance difference in the prevalence of sarcoid in relation to sex, males were more likely affected by sarcoid infection as compared to females with a prevalence of $9.1 \%$ as indicated in Table 2 below. According to age and service category, young age groups were less likely affected as compared to adults although there was no statistical difference observed during analysis; whereas working donkeys with a prevalence of $8.2 \%$ were more likely affected in relation to non working donkeys. This was statistically significant difference recorded in relation to service category $(\mathrm{p}<0.05)$ indicated below in Table 2.

\begin{tabular}{|c|c|c|c|c|}
\hline Risk factor & No. examined & $\begin{array}{l}\text { Sarcoid } \\
\text { positive }\end{array}$ & Prevalence & P-value \\
\hline \multicolumn{5}{|l|}{ Sex } \\
\hline Female & 219 & 15 & 6.8 & 0.453 \\
\hline Male & 175 & 16 & 9.1 & \\
\hline \multicolumn{5}{|l|}{ Age } \\
\hline$>2$ & 40 & 2 & 5 & 0.428 \\
\hline 02-Oct & 265 & 24 & 9 & \\
\hline$>10$ & 89 & 5 & 5.6 & \\
\hline \multicolumn{5}{|c|}{ Service category } \\
\hline Non working & 28 & 1 & 3.5 & 0.001 \\
\hline
\end{tabular}




\section{Working}

$$
366
$$

30

$$
8.2
$$

Table 2: Prevalence of sarcoid in relation to sex, age, and service category of donkeys.

\section{Type of sarcoid and their anatomical distribution}

During the study five clinical types of sarcoids were diagnosed; such as fibroblastic (32.3\%), nodular (29.0\%), occult (16.1\%), mixed (12.9\%) and verrucous $(9.7 \%)$ sarcoid. Fifty one percent of the sarcoids were often detected in the neck and head, followed by trunk and genital (32.3\%) and limb and shoulder areas (16.1\%).

About 6.5\% (2/31) sarcoid were detected in sites where previous history of wound was occurred. The survey result from donkey owners on the nature of the tumors indicated that the transition of the occult, verrucous and nodular sarcoids in to fibroblastic type. Sarcoids experience different kinds of growth patterns some were static for long periods most of the case manifest moderate increment in size; $83 \%$ $(26 / 31)$ sarcoid was increasing in size while $16.1 \%(5 / 31)$ sarcoid was static in nature. According to information observed from the owners' interview, the rate of transition was faster for sarcoids grown on parts of the body exposed to harness and other work related injuries.

\section{Principal health and welfare impact of sarcoid}

The principal effects of sarcoid observed during study on animals were debilitation, epipheral, fly worry and bleeding. Apparent blindness, difficulties in defecation, locomotion, parturition, urination, grazing, and mastication were the most principal effects of sarcoids were observed depending on the site of development of the mass due to further locally invasive nature of disease.

\section{Discussion}

Sarcoid has a noticeable impact on equine health and welfare and present a significant financial burden for owners who are dependent on their single donkey for their various daily income activities as the mass can cause loss of use of the donkeys. The economic repercussion can be great besides the cosmetic aspects; the normal use of the donkey can be hindered, especially when tumors are located at the level of the girth and bridle, distal limbs, corner of the mouth, eyelids [3].

The present study revealed that from the total of 394 examined donkeys, 31 (7.9\%) was diagnosed sarcoid positive. Even though there was not significance difference was found, the prevalence of sarcoid in Ada'a was higher as compare to Akaki. The reason underlying such relatively high prevalence may be attributed due to lower attention in proper handling their animals during working time. Previous findings indicated that improper handling as well as sharing infected harness from animal to animal aggravates the occurrence of sarcoids. This finding was harmonious with results of Keith and Tibebu $[9,10]$.

There were controversial reports on the age groups and sexes of equine affected by sarcoids. Epidemiological observations on sarcoids in a population of donkey in the donkey sanctuary, Uk has indicated that the disease was most frequently occur in younger male donkeys in their first five years of age. Similarly, Marcanne and Kottenbelt [5] reported that $70 \%$ of sarcoids occur in equine less than four years of age; whereas Keith et al. [9] have concluded that there were no predilections for age, sex, breed, color or season of the years. The present study has also demonstrated that there were no specific preference to sex $(8.2 \%$ male and $3.5 \%)$ and age. The relative higher risk of the disease in young donkeys was in agreement with study carried out in the DHWP which indicated that sarcoid occurs more frequently at age range of 3-6 years $[3,10]$. Reid has indicated castration as the possible risk factor for the relative increased incidence of sarcoid in male donkeys [11].

The present study further strengthen that there was no complaint of castration by interviewed owners for the occurrence of sarcoid. Chambers et al. suggested that skin trauma, the immunological status and the genetic constitution of the individual animal play an important role for the occurrence of equine sarcoid [7]. Reid et al. reported that the main cause for the spread of sarcoids in donkeys is direct daily contact between affected animals assumed as a transmissible agent [11]. In the present study, although there was no report from the interviewed owners about the transmission of sarcoid by direct contact, about $6.5 \%$ (2 of 31 ) sarcoid was observed in site where there was back sore. This might indicate that there is a potential factor for the transmission sarcoids between donkeys potentially due to sharing infected harnesses.

During the study period, five clinical types of sarcoids were diagnosed; such as fibroblastic (32.3\%), nodular (29.0\%), occult $(16.1 \%)$, mixed $(12.9 \%)$, and verrucous $(9.7 \%)$ sarcoids. The highest percentage of fibroblastic type of sarcoids might be associated with the transition of the other forms of sarcoids to fibroblastic type following traumatic injuries [12]. In present study, the body predilection sites of sarcoids were similar with Tibebu [10] who has demonstrated that sarcoid most often occurred on the head and neck area $(53.8 \%)$, followed by trunk and genitalia (24.2\%) and limb and shoulder area (22\%) unlike Ayele et al. [3] who have reported sarcoid predisposition on the limbs and shoulder (59.8\%) followed by head and neck (33.1\%) and trunk including the male and female genitalia (7.1\%). The reason for the differences observed for the high occurrence of sarcoids in head and neck areas is probably the exposure frequency of these anatomical parts to different traumatic agents in the working environment of the donkeys.

The principal effect of sarcoids mainly depends on the site of development of the mass. At the time of study weight loss, bleeding, epiphora and fly worrying was observed. Most of sarcoid (83.9\%) was increasing in size. The reason is more probably improperly treated sarcoid by traditional healers and owners. The owners or traditional healers use sharp metal to cut the mass with improper manual restraining which favors autoinoculation of disease, in addition, they don't take in to account margin and depth of the masses which also facilitate the recurrence of the mass in more aggressive form. Pascoe and Knottenbelt have recommended that incomplete excision can precipitate rapid fibroblastic proliferation which can be difficult if not impossible to treat successfully [12]. Due to its locally invasive nature of tumor; might be resulted in apparent blindness, difficulties in locomotion, urination, grazing, mastication and defecation depending on the site of development.

In conclusion, present study suggest that Sarcoid is a life threating disease in working donkeys. It is also an economic problem for owners especially for those who are dependent only on the burdens of donkeys as a means of acquiring their income. Therefore, Improvement of presently available methodologies of harnessing so as to reduce incidence of back/saddle sore problem through enhancing awareness of donkey owners to realize the consequences of faulty interference of sarcoid should be important. Also, further studies should have to be 
Citation: Gebre D, Gizachewu A, Negero J (2018) Equine Sarcoid: Epidemiology and its Clinical Impact in Working Donkeys in Selected Districts of Central Ethiopia. J Vet Sci Technol 9: 537. doi:10.4172/2157-7579.1000537

Page 4 of 4

conducted on the diagnosis and treatment measures of donkey sarcoids.

\section{References}

1. Marti E, Lazary S, Antczak DF, Gerber H (1993) Report of the 1st International Workshop on Equine Sarcoid. Equine Vet J 25: 397-407.

2. Brostrom H (1995) Equine sarcoids. A clinical and epidemiologic study in relation to equine leukocyte antigens (ELA). Acta Vet Scand 36: 223-236.

3. Ayele G, Feseha G, Bojia E, Getachew M, Tesfaye M, et al. (2007) Sarcoid: Clinical epidemiology, principal effect and treatment responses. In proceedings of the 5th international colloquium on working equines, Addis Ababa, Ethiopia.

4. Foy JM, Rashmir-Raven AM, Brashier MK (2002) Common equine skin tumors. Compendium on Continuing Education for the Practicing Veterinarian 24: 242-255.

5. Sloet MM, Oesterbaan O, Knottenbelt DC (2001) The practitioner guide to equine dermatology. Libre BV Publisher, pp: 28-30.

6. Bagaert L, Martens A, De Baere C, Gasthuys F (2005) Detection of bovine papillomavirus DNA on the normal skin and in the habitual surroundings of horses with and without equine sarcoids. Res Vet Sci 79: 253-258.

7. Chambers G, Ellsmore VA, Brien PMO, Ried SWJ, Love S, et al. (2003) Association of bovine papilloma virus with the equine sarcoid. J Gen Virol 84: 1055-1062.

8. Thrusfield M (2005) Veterinary Epidemiology. 2nd edn, Blackwell Science Ltd, Oxford, UK, pp: 187-189.

9. Keith P (2005) Survey into the factors affecting the health and welfare of donkeys and mules in Tigray and Amhara regions of northern Ethiopia. Faculty of Veterinary Medicine, Addis Ababa University, Debre Zeit, Ethiopia.

10. Tibebu D (2009) Clinical epidemiology and principal health effects of sarcoids in Donkeys of central Ethiopia (Shoa). Nature and Science 15: 82-88.

11. Reid SWJ, Gettinby G, Fowler JN, Ikin P (1994) Epidemiologic observations on sarcoids in a population of donkeys (Equus-Asinus). Vet Rec 134: 207-211.

12. Mohammed HO, Rebhun WC, Antczak DF (1999) Factors Associated with the Risk of Developing Sarcoid Tumors in Horses. Equine Vet J 24: 165-168. 